\title{
GRANULATION OF POULTRY MANURE AND BIOCHAR FOR PRODUCTION OF ORGANIC FERTILIZERS
}

Egle Jotautiene $^{1}$, Ramunas Mieldazys ${ }^{1}$, Aloyzas Gaudutis ${ }^{1}$, Aivars Aboltins ${ }^{2}$

\author{
${ }^{1}$ Vytautas Magnus University, Lithuania; ${ }^{2}$ Latvia University of Life Sciences and Technologies, Latvia \\ egle.jotautiene@vdu.lt, ramunas.mieldazys@vdu.lt, aloyzas.gaudutis@gmail.com, \\ aivars.aboltins@1lu.lv
}

\begin{abstract}
Intensive agriculture and chemical farming deplete the soils. The growing demand for organic agricultural products encourages the use of nature-friendly, natural materials used for soil fertilization. Many farmers are already using granular organic fertilizers made from manure, meat-and-bone meal and others. Granular organic fertilizers are easier to handle, transport, store and spread in soils. Biochar is also intensively researched as a substance for improving soil quality, plant growth and reducing greenhouse gas emissions from soil. The benefits of biochar are known for the physical properties of the soil, which manifests in changes in the soil density and water holding capacity. However, the preparation of manure and biochar for granulation has significant differences compared to other organic materials, due to the moisture, density, fractional composition and other parameters of the granulated material. This requires the determination of the physical and mechanical properties of both the raw material and the final product. The article deals with the physical and mechanical properties of granular fertilizers from poultry manure and biochar. Moisture of different raw organic materials was determined, which is important for the granulation process. The density, bulk density, fractional composition, moisture and compressive strength properties of manure with biochar, raw material and granules made from it, produced in different technological regimes, were experimentally investigated. The obtained results showed that it is expedient to enrich manure granules with biochar.
\end{abstract}

Keywords: natural materials, granular fertilizers, physical-mechanical properties, biochar, poultry manure.

\section{Introduction}

The growing demand for organic agricultural products encourages the use of environmentally friendly natural materials for soil fertilization. Currently, only about 5\% of bio-waste is recycled in Europe. Intensified use of organic fertilizers could reduce the need for mineral fertilizers by up to $30 \%$ [1]. As the environmental and ecological requirements of the EU and Lithuania become stricter, attention is increasing to recycling, reuse or other waste management. In line with the circular economy principle, all organics of plant origin should be returned to the economic cycle.

Agriculture generates a lot of organic waste that could be used for fertilizer production. This would implement the principles of the circular economy and reduce environmental pollution by replacing inorganic fertilizers with organic ones. At present, with the expansion of agricultural production, it is necessary to rationally manage the amount of manure generated [2]. And forest management leaves forest waste that can be recycled into by-products. In order to meet the commitments of sustainable development all agricultural waste must be used in accordance with the principles of the circular economy.

Biochar is intensively studied as a substance for improving soil quality, plant growth and reducing greenhouse gases from the soil. The benefits of biochar are known for the physical properties of the soil, which manifests as a change in the soil density and water holding capacity [3]. A significant number of farmers already use granular organic fertilizers made from manure, meat-and-bone meal and others. Granular organic fertilizers are easier to handle, transport, store and spread in soils. When the content of nutrients in the soil microflora in granular fertilizers is optimal, they dissolve quickly in water and are easily absorbed by plants [4].

Granulation of organic waste requires a granulation system, which consists of equipment for drying, grinding, dust collection, granulation, granule cooling. Granule strength is a necessary property in anticipating the use and storage of organic fertilizers. The preparation of manure and biochar for granulation and the granulation process have significant differences compared to other organic materials, due to the moisture, density, fractional composition and other parameters of the granulated material [5]. To do this, it is necessary to determine the physical and mechanical properties of both the raw material and the granule blank. By analyzing the results of the other experiments for the mixtures used in granulations with different percentage compositions of chicken manure and straw, it can be 
found that the hardness of granulate significantly increases together with greater contents of chicken manure and smaller contents of straw [6].

\section{Materials and methods}

Experimental investigations of poultry manure and biochar waste preparation and conversion into granular fertilizers were carried out in 2021, in a laboratory based at the Institute of Agricultural Engineering and Safety in Lithuania. The poultry manure used in this study was obtained from an industrial poultry farm. A total of $6 \mathrm{~kg}$ of pure poultry manure samples and $6 \mathrm{~kg}$ manure with litter were collected from different places in the poultry farm. As litter wood sawdust was used in the farm. Manure has been stored for 3 weeks inside the building. Biochar made from wood was submitted by the company "Cocos LT" in Lithuania.

Raw material preparation. Manure samples were dried for 24 hours in the ventilation canal with slow heated air flow. The manure material was placed to the hammer mill GMM-1 (Lithuabua), where it was grinded in fine powder like form. Biochar was not milled. Poultry manure and biochar material were mixed thoroughly to achieve homogeneity. Samples of $1.5 \mathrm{~kg}$ each were prepared for granulation. Poultry manure and biochar sample codes, proportions and mixing ratios (weight to weight) are presented in Table 1.

Table 1

Poultry manure and biochar sample codes

\begin{tabular}{|c|l|}
\hline Sample code & \multicolumn{1}{|c|}{ Sample ratio (wt/wt, \%) } \\
\hline 1MC & Pure poultry manure \\
\hline 2MC & 8 parts of manure to 1 part of biochar (ratio of 87.5/12.5) \\
\hline 3MC & 4 parts of manure to 1 part of biochar (ratio of 75/25) \\
\hline 4MC & 1 part of manure to 1 part of biochar (ratio of 50/50) \\
\hline 1MKC & Pure poultry manure with litter \\
\hline 2MKC & 8 parts of manure with litter to 1 part of biochar (ratio of $87.5 / 12.5$ ) \\
\hline 3MKC & 4 parts of manure with litter to 1 part of biochar (ratio of $75 / 25$ ) \\
\hline 4MKC & 1 part of manure with litter to 1 part of biochar (ratio of 50/50) \\
\hline
\end{tabular}

Milling quality was determined, the mass fraction composition of these manure types and biochar was determined using a sieve shaker Retsch AS 200 (Germany) and sieves with holes of various diameters: $0.25 \mathrm{~mm}, 0.5 \mathrm{~mm}, 0.63 \mathrm{~mm}, 1 \mathrm{~mm}, 2 \mathrm{~mm}, 3.15 \mathrm{~mm}, 4 \mathrm{~mm}$ and $5 \mathrm{~mm}$. The mass remaining on the sieves is weighted, and the sample part of every fraction in percentage is calculated [7].

Density of mill was determined in the $6 \mathrm{dm}^{3}$ cylinder vessel, which was filled by mass till the upper edge and weighted. Moisture of mill is determined according to the standard methodology (EN 12048:1996). For mill pressing and granule production the low-power $(7.5 \mathrm{~kW})$ granulator ZLSP200B (Poland) with a horizontal $6 \mathrm{~mm}$ matrix was used. Before granulation, raw material mill samples $(1.5 \mathrm{~kg}$ each) were moistened by spraying them with water, because the granulation process requires the addition of moisture, all conditions were repeated according to the previous experiments [7; 8]. Cylindrical granule volume was calculated using the granule size (diameter and length). After determination of the granule volume and weight, the density of all investigated granule samples was calculated [7]. Each test was repeated 3 times. The analysis of variance with three replications design was performed on the data of the fulfilled experiments, using analysis of variance to determine significance at $95 \%$ probability level.

Granule strength tests were performed with a $5 \mathrm{kN}$ capacity Instron 5965 test machine (USA). The received parameters were saved to the Instron Bluehill test control software. The cylindrical granules were horizontally placed between two anvils and a compressive force was applied to the side of the granule. The tester was run at a compression rate of $20 \mathrm{~mm} \cdot \mathrm{min}^{-1}$ and was stopped after the granule had broken [7]. Each test was performed 5 times per granule type sample. Statistical methods were used for processing the obtained data. The average values and their confidence intervals (CI) were calculated at a probability level of $95 \%$. 


\section{Results and discussion}

Having performed experimental research, the physical-mechanical characteristics - the moisture content and bulk density of milled by hammer mill poultry manure were determined. Pure poultry manure samples were $62.81 \pm 2.48 \%$, manure with litter $56.06 \pm 0.58 \%$ and biochar $27.35 \pm 3.68 \%$ initial moisture content. After artificial drying the moisture content and bulk density of milled samples by mill GMM-1 were determined (Table 2).

Table 2

Physical-mechanical characteristics of poultry manure and biochar mill and granules (DM - dry material)

\begin{tabular}{|c|c|c|c|}
\hline $\begin{array}{c}\text { Sample } \\
\text { code }\end{array}$ & $\begin{array}{c}\text { Mill moisture content, } \\
\text { \% }\end{array}$ & Mill bulk density, $\mathbf{~ k g} \cdot \mathbf{m}^{-3}$ & $\begin{array}{c}\text { Produced granule } \\
\text { density, } \mathbf{~ k g}^{-\mathbf{3}}\end{array}$ \\
\hline 1MC & $9.39 \pm 3$ & $635.7 \pm 18.66(576.0 \mathrm{DM})$ & $1609.01 \pm 79.57$ \\
\hline 2MC & $8.15 \pm 1.9$ & $555.2 \pm 15.20(509.9 \mathrm{DM})$ & $1555.65 \pm 80.34$ \\
\hline 3MC & $8.62 \pm 0.1$ & $534.7 \pm 5.57(488.7 \mathrm{DM})$ & $1470.22 \pm 69.00$ \\
\hline 4MC & $9.16 \pm 1.64$ & $457.4 \pm 11.85(415.5 \mathrm{DM})$ & $1369.43 \pm 108.80$ \\
\hline 1MKC & $17.50 \pm 2.78$ & $410.9 \pm 24.95(339.0 \mathrm{DM})$ & $1300.57 \pm 31.27$ \\
\hline 2MKC & $16.76 \pm 2,42$ & $406.8 \pm 16.65(338.7 \mathrm{DM})$ & $1350.16 \pm 35.78$ \\
\hline 3MKC & $15.80 \pm 1.5$ & $398.1 \pm 27.15(335.2 \mathrm{DM})$ & $1220.29 \pm 112.57$ \\
\hline 4MKC & $15.40 \pm 0.98$ & $390.8 \pm 9.72(330.6 \mathrm{DM})$ & $1189.73 \pm 50.71$ \\
\hline
\end{tabular}

As it may be seen from Table 2, the bulk density of the sample 4MKC by mill is the smallest $390.8 \mathrm{~kg} \cdot \mathrm{m}^{-3}$, and the density of $1 \mathrm{MC}$ without biochar is almost 2 times bigger $635.7 \mathrm{~kg} \cdot \mathrm{m}^{-3}$.

Fraction composition of manure mass was determined applying the methodology widespread in the EU countries; it was done using sieves with holes of various diameters. Poultry manure fractional composition (\%) dependence on the sieve hole diameter $(\mathrm{mm})$ is shown in Fig. 1 and Fig. 2.

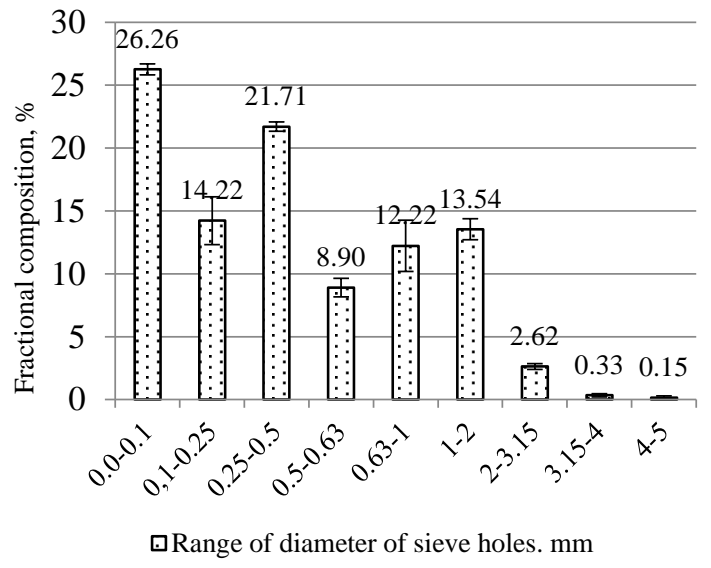

Fig. 1. Fraction composition of poultry manure

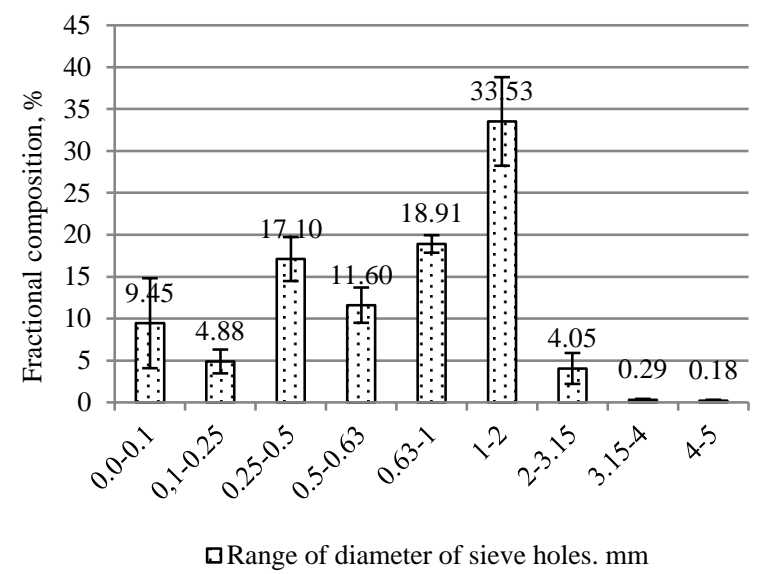

Fig. 2. Fraction composition of poultry manure with litter

Having evaluated the fraction composition of mill, we may see that the highest fraction of poultry mill accumulated on the sieve with holes $0.1 \mathrm{~mm}$ diameter $-26.26 \pm 3.5 \%$, which are in the smallest fraction near to dust, and high amount of fraction accumulated on the sieve with holes $0.5 \mathrm{~mm}$ diameter $-21.71 \pm 2.2 \%$. Dependence of a part of poultry manure with litter mill fraction (\%) on the holes of sieves is presented in Fig. 2. After evaluation of factional mill composition from the chart we can see that the highest fraction of manure with litter mill accumulated on the sieve with holes till $2 \mathrm{~mm}$ diameter $-33.53 \pm 2.9 \%$ and in the second place it is on $1 \mathrm{~mm}$ diameter holes sieve $-18.91 \pm 2.5 \%$. There was no significant amount of fraction on the sieve with holes $3.15 \mathrm{~mm}$ diameter in both variants. Fraction composition of biochar is presented in Fig. 3.

The character of biochar dispersion on a sieve is similar to poultry manure with litter dispersion, big amount of biochar fraction accumulated on the sieve with round holes $2 \mathrm{~mm}$ diameter $35.80 \pm 2.6 \%$ of the mass. The smallest quantity of dust was got when sieving biochar, only $4.76 \pm 1.3 \%$. 


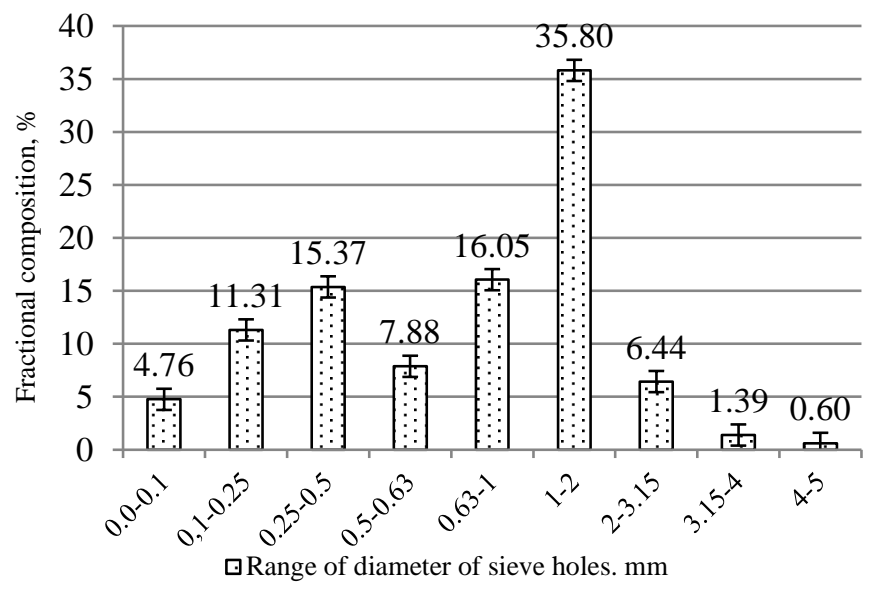

Fig. 3. Fraction composition of biochar

All investigated mass is suitable for granulation after appropriate preparation. In order to continue using the mass for fertilizer purposes, the investigated material was pressed in granules and the biometric parameters were determined. It has been determined that the produced granulated fertilizers were in the range of the granule diameter from $6.03 \pm 0.9 \mathrm{~mm}$. Average granule weight was $0,61 \pm 0.9 \mathrm{~g}$. Granule average length $13.2 \pm 5.6 \mathrm{~mm}$. Granulating raw material with such kind of traditional granulator, with a horizontal granulator matrix, we got big granule length scattering. The analysed and determined density parameters of granulated organic fertilizer granules are presented in Table 1.

As it is seen from the presented in the table characteristics, pure poultry manure granules (MC series) have high density (till $1609.01 \pm 79.57 \mathrm{~kg} \cdot \mathrm{m}^{-3}$ ). Biochar additive reduces the density of the granules in all cases. Poultry manure with litter (MKC series) show smaller density characteristics.

Granule strength ensures that a fertilizer will arrive at its destination as intended and can be used without breaking down into finer particles. The strength test curves are shown in Figure 4 and 5. From five samples an average inherent curve was chosen, on purpose, to show the character of the force variation in the strength test for each granule series type. Analysing the deformation curves, it can be observed that the maximum crushing force was more than $427 \mathrm{~N}$ in the $1 \mathrm{MC}$ sample case (Figure 4) and that sample showed the greatest strength result.

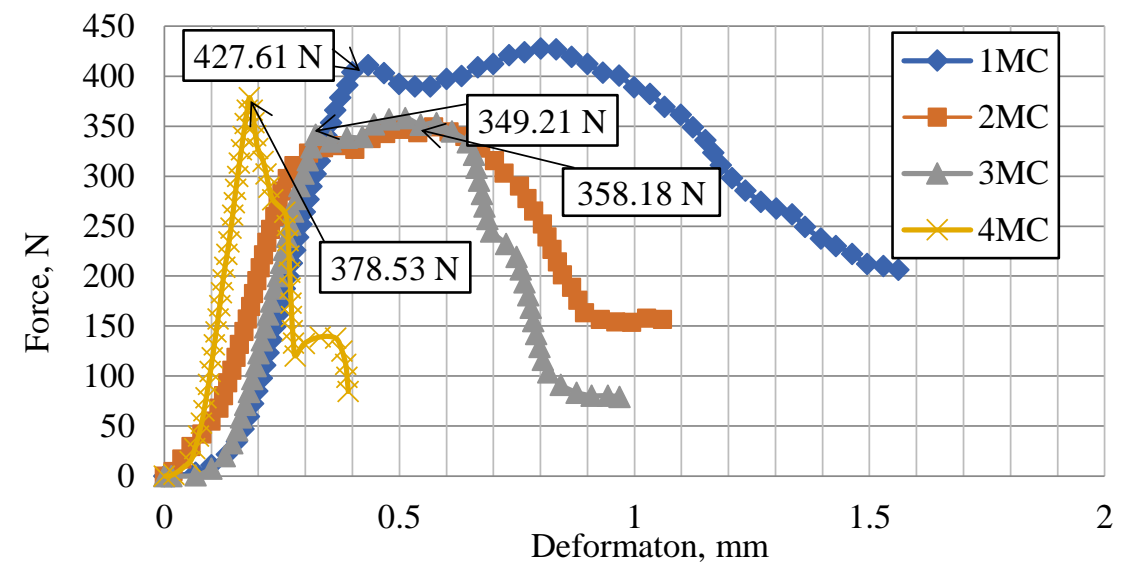

Fig. 4. Strength test of poultry manure and biochar granules (MC series) in horizontal orientation

The poultry manure with litter and biochar granules did not disintegrate immediately due to their elasticity properties (Figure 5). Most of deformation begins at $0.1 \mathrm{~mm}$ and continues till $0.7 \mathrm{~mm}$. The best strength result was also shown by the poultry manure sample without the addition of biochar in $1 \mathrm{MKC}$ case $(766.4 \mathrm{~N})$. 


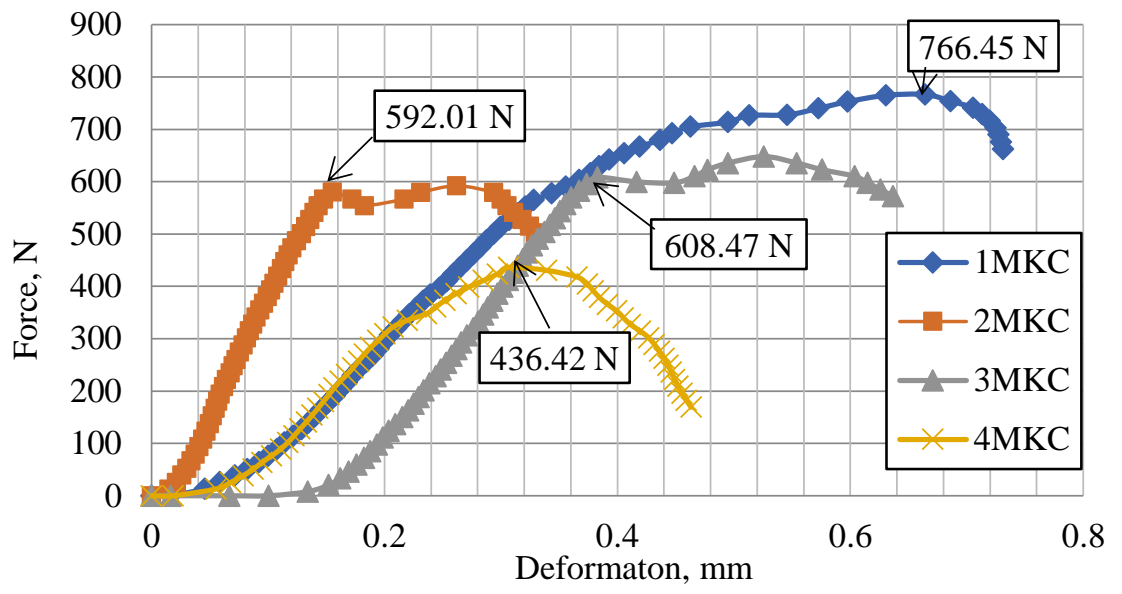

Fig. 5. Strength test of poultry manure with litter and biochar granules (MKC series) in horizontal orientation

It was determined that all experimental granule samples, under a force of about $350 \mathrm{~N}$ in the horizontal direction, were totally disintegrated. The experimental results presented in Figure 6 show that the average strength of the poultry manure granules (MC series) was around $392.1 \pm 75.6 \mathrm{~N}$ in the horizontal direction. Increasing the concentration of biochar has presented weaker binding properties in the other MC series samples. Granule sample MC1, with a semi-static stability of $471.2 \mathrm{~N}$, was found to be the most mechanically stable. The poultry manure with litter and biochar granules (MKC series), with a static stability of $846.3 \mathrm{~N}$, were found to be the most mechanically stable (in 1MKC case). The semi-static stability of all MKC series granules was $604.1 \pm 202,6 \mathrm{~N}$. It is almost twice compared with $\mathrm{MC}$ series. But the weaker granules are still suitable for use as a fertilizer, because such granules dissolve into the soil easier. For comparison, the average pig manure compost granule strength was $628.3 \pm 38.9$ $\mathrm{N}$ [7]. In other experiments, where poultry manure and biomass ash granulation perspectives were investigated, the granule strength ranged from $140.3 \mathrm{~N}$ to $312.6 \mathrm{~N}$ [8]. According to other scientists, the mechanical strength of pellets made with a similar ZPL series granulator from chicken manure mixed with chopped rye straw varied from 290 till $465 \mathrm{~N}$ [6].

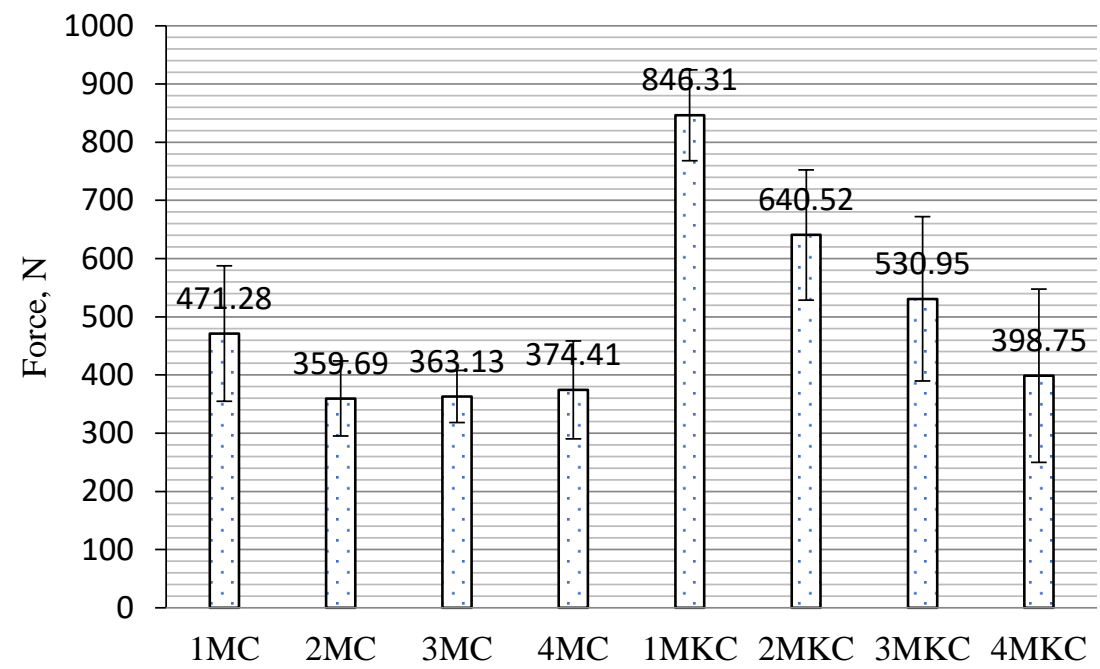

Fig. 6. Poultry manure and biochar granule strength test (1MC - pure poultry manure; $2 \mathrm{MC}$-manure and biochar (ratio of 87.5/12.5); 3MC - manure and biochar (ratio of 75/25);

$4 \mathrm{MC}$ - manure and biochar (ratio of $50 / 50$ ); $1 \mathrm{MKC}$ - pure poultry manure with litter; $2 \mathrm{MKC}$ - manure and biochar (ratio of 87.5/12.5); 3MKC - manure and biochar (ratio of 75/25); $4 \mathrm{MKC}$ - manure and biochar (ratio of 50/50) 
The tested granules were sufficiently resistant to operating loads, easy to transport and can be mechanically spread and inserted into the soil. The research results of poultry manure and biochar usage for fertilizer purposes will be presented in a separate article.

\section{Conclusions}

1. Having evaluated the fraction composition of mill, we may see that the highest fraction of poultry mill accumulated on the sieve with holes $0.1 \mathrm{~mm}$ diameter $-26.26 \pm 3.5 \%$, which are in the smallest fraction near to dust. Poultry manure with litter mill accumulated on the sieve with holes till $2 \mathrm{~mm}$ diameter $(33.53 \pm 2.9 \%)$. There was no significant amount of fraction on the sieve with holes $3.15 \mathrm{~mm}$ diameter in both variants. The character of biochar dispersion on the sieve is similar to poultry manure with litter dispersion, big amount of biochar fraction accumulated on the sieve with round holes $2 \mathrm{~mm}$ diameter $(35.80 \pm 2.6 \%)$.

2. The determined initial moisture content of the raw materials ranged in $62.81 \pm 2.48 \%$ in pure poultry manure, $56.06 \pm 0.58 \%$ in manure with litter and $27.35 \pm 3.68 \%$ in biochar. After drying and material mixing the moisture content varied from $8.15 \pm 1.9$ to $17.50 \pm 2.78 \%$. The bulk density of the raw material was the lowest in the 4 MKC sample case $\left(390.8 \pm 9.72 \mathrm{~kg} \cdot \mathrm{m}^{-3}\right)$ and the bulk density of $1 \mathrm{MC}$ was the highest $\left(635.7 \pm 18.66 \mathrm{~kg} \cdot \mathrm{m}^{-3}\right)$, The granule density was obtained from $1189.73 \pm 50.7 \mathrm{~kg} \cdot \mathrm{m}^{-3}$ (in $4 \mathrm{MKC}$ case) to $1609.01 \pm 79.5 \mathrm{~kg} \cdot \mathrm{m}^{-3}$ (in $1 \mathrm{MC}$ case) after granulation.

3. Increasing biochar content in poultry manure raw material, from 0 till $50 \%$ in the raw material led to the strength decrease; from 471.2 to $359.6 \mathrm{~N}$ on average in MC series case. Increasing biochar content in poultry manure with litter raw material led to the strength decrease; from 846.3 to $398.6 \mathrm{~N}$ on average in MKC series case.

4. The results of this study suggest that granulation of a manure/biochar mixture using biomass granulators with horizontal matrix produces granules of high density and granular strength. It can be argued that the materials of poultry manure and biochar can be granulated, but better strength results are possible to achieve with lower biochar additives.

\section{References}

[1] European Commission (EC) 2016. Press release Circular economy: New Regulation to boost the use of organic and waste-based fertilizers. [online] [31.03.2019]. Available at: http://europa.eu/rapid/press-release_IP-16-827_en.htm

[2] Official Statistic Portal, 2021. [online] [8.01.2021]. Available at: https://osp.stat.gov.lt/EN/statistiniu-rodikliu-analize?hash = af9953af-3ff9-4d90-8c926335ddc0c012\#I

[3] Pokharel P., Chang S. X. Manure pellet, woodchip and their biochars differently affect wheat yield and carbon dioxide emission from bulk and rhizosphere soils. Science of the Total Environment, vol. 659, 2019, pp. 463-472.

[4] Mazeika R., Staugaitis G., Baltrusaitis J. Engineered pelletized organo-mineral fertilizers (OMF) from poultry manure, diammonium phosphate and potassium chloride. ACS Sustainable Chemistry \& Engineering, vol. 4(4), 2016, pp, 2279-2285. DOI: 10.1021/acssuschemeng.5b01748.

[5] Kalus K., Koziel J. A., Opalinski S. A review of biochar properties and their utilization in crop agriculture and livestock production. Applied Sciences, vol. 9(17), 3494, 2019. DOI: $10.3390 / a p p 9173494$

[6] Zdanowicz A., Chojnacki J. Mechanical properties of pellet from chicken manure mixed with chopped rye straw. Journal of Research and Applications in Agricultural Engineering, vol. 62 (4), 2017, pp. 216-218.

[7] Mieldažys R., Jotautienė E., Zinkevičienè R., Jasinskas A. Manure processing into granular fertilizers using additional additives. Proceedings of International conference "Engineering for rural development", May 22-24, 2019. Jelgava: Latvia University of Life Sciences and Technologies, 2019, vol. 18. pp. 635-640.

[8] Mieldažys R., Jotautienè E., Jasinskas A. The opportunities of sustainable biomass ashes and poultry manure recycling for granulated fertilizers. Sustainability, vol. 11(16), 4466, 2019. DOI: $10.3390 /$ su11164466 